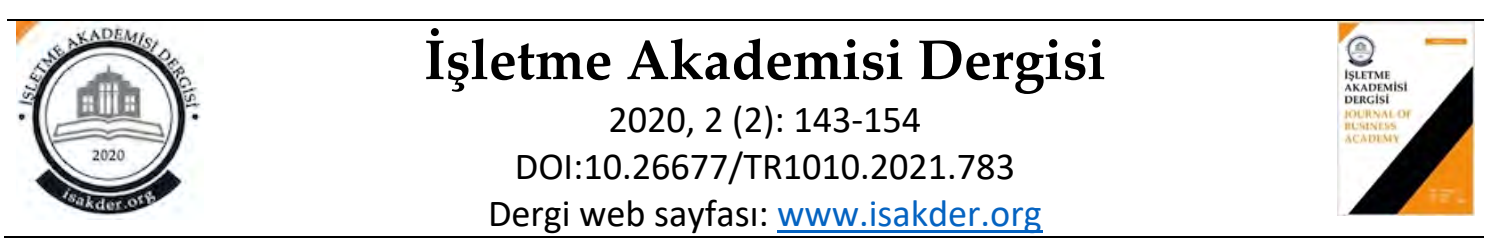

Derleme Makalesi

\title{
Dijital Kanallar ve Sağlık Hizmetlerinde Hile
}

\section{Doç. Dr. Hilal ÖZEN}

Trakya Üniversitesi, İktisadi ve İdari Bilimler Fakültesi, İşletme Bölümü, Edirne/Türkiye hilalozen@trakya.edu.tr , www.orcid.org/0000-0002-2566-5098

\section{Öz}

Günümüzde sağlık hizmetleri alanında önemli gelişmeler yaşanmaktadır. Bu gelişmelerden en göze çarpanı, pek çok sağlık hizmetinin artık dijitalleşmeye başlaması, dolayısıyla dijital kanalların kullanılarak bu hizmetlere erişimin daha kolay sağlanabilir hale gelmesidir. Sağlık hizmeti veren kurumlar hizmetlerini bu kanallar vasıtası ile sunmaya çalışırlarken sağlıkla ilgili ürün satışı yapan kuruluşlar ve eczaneler de dijital kanallardan e-ticaret faaliyetleri sunabilmektedirler. Özellikle sağlık hizmeti veren hastane ve klinik tarafında maalesef bu alanda yaşanan hile ve dolandırıcılık durumlarına rastlanılması karşılaşılan olumsuz durumlar arasında yer alabilmektedir. Hile ve dolandırıcılık, hastane yönetimi, sağlık hizmeti sağlayanlar ya da hastalar kaynaklı durumlar sebebiyle meydana gelebilmektedir. Sağlık hizmetlerinin dijital kanallara taşınması ile birlikte hastalarla temas noktaları da çeşitlenmiştir. Tüketiciler için değer yaratma prensibine dayanan pazarlama faaliyetleri sağlık kurumlarında da sunulan tüm hizmet süreçleri içerisinde yer alırken farklı pazarlama kanalları ve stratejileri ile bu işlevini pekiştirmektedir. Ancak, sağlık hizmetlerinde geleneksel kanallarda yaşanılan hile durumları maalesef dijital kanallarda ve pazarlama faaliyetlerinde de karşımıza çıkmaktadır. Bu çalışmada sağlık hizmetlerinde dijital kanallarda yaşanılan hile ve dolandırıcılık kavramlarına dikkat çekilmeye çalışılmıştır.

Anahtar Kelimeler: Pazarlama, Dijital Pazarlama, Dijital Sağlık Hizmetleri, Hile.

Makale Gönderme Tarihi: 25.05.2021

Makale Kabul Tarihi: 07.06.2021

\section{Önerilen Atıf:}

Özen, H. (2021). Dijital Kanallar ve Sağllk Hizmetlerinde Hile, İşletme Akademisi Dergisi, 2(2): 143-154.

(c) 2021 İşletme Akademisi Dergisi. 


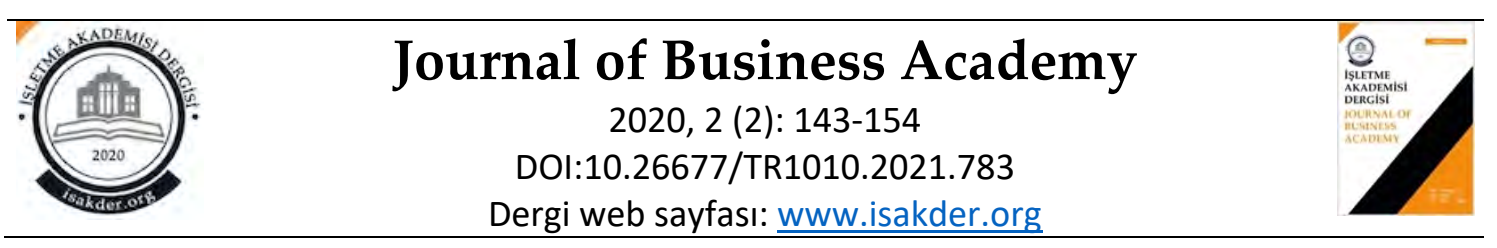

$\underline{\text { Review Article }}$

\title{
Digital Channels and Fraud in Healthcare
}

\author{
Assoc. Prof. Hilal ÖZEN \\ Trakya University, Faculty of Economics and Administrative Sciences, Department of Business \\ Administration, Edirne, Turkey. \\ hilalozen@trakya.edu.tr, www.orcid.org/0000-0002-2566-5098
}

\begin{abstract}
There are significant improvements in healthcare industry. The most prominent of these developments is the fact that many health services have started to digitalize, access to these services has become easier by using digital channels. While health care institutions try to offer their services through these channels, organizations that sell health-related products and pharmacies can also handle their e-commerce activities through digital channels. Especially in hospitals and clinics providing health services, fraudulent activities in this area can be among the negative situations encountered. Here, fraud situations may arise due to hospital management, healthcare providers or patients. With the transfer of healthcare services to digital channels, contact points with patients have also diversified. While marketing activities based on the principle of creating value for customers are included in all service processes in health institutions, it reinforces this function with different marketing channels and strategies. However, unfortunately, cases of fraud experienced in traditional channels in health services are also encountered in digital channels and marketing activities. This study tried to draw attention to the concepts of fraud experienced in digital channels in healthcare services.
\end{abstract}

Keywords: Marketing, Digital Marketing, Digital Healthcare Services, Fraud.

Received: 25.05 .2021

Accepted: 07.06.2021

\section{Suggested Citation:}

Özen, H. (2021). Digital Channels and Fraud in Healthcare, Journal of Business Academy, 2(2):

143-154.

(C) 2021 Journal of Business Academy. 


\section{1- Giriş}

Günümüzün önemli bir sektörü haline gelen sağllk sektörü COVID-19 salgının da etkisiyle her yaş grubundan bireyin önemsediği ve dikkate aldığı alanlar arasında girmiştir. Şimdiye kadar sağlığı hakkında çok fazla titiz davranmayan kişiler bile sağlığına daha çok dikkat eder olmuş ve bu konuda bilgilendirici içerikleri pek çok kanaldan takip etmeye başlamışlardır. Ayrıca, salgın sebebiyle fiziksel manada sağlık hizmeti almaya çekinen bireylerin sayısının artması ile de birlikte sağlıkta dijitalleşme kavramı öne çıkmış ve bu konuda farklı kanallar devreye girmeye başlamıştır. Esasen sağlıkta dijitalleşme yeni bir kavram değildir, eskilere dayanmakla birlikte son senelerde ivme kazanmıştır.

Sağlık sektöründe dijitalleşme başlangıcı aslında bu alanda bilgisayarların kullanılmaya başlaması ile birlikte 19601 yıllara kadar uzanmaktadır. Bu yıllarda daha çok yönetimsel tarafta kullanılan teknolojiler 80lere gelindiğinde klinik tarafta da kullanılmaya başlanmıştır. Sonrasında ise bilgi ve iletişim teknolojilerinde (BIT/ICT) meydana gelen hızlı gelişmeler, bu alanda da pek çok diğer alanda olduğu gibi iş yapış süreçlerinin dijitalleşmesini beraberinde getirmiştir (Şimşek ve Karaismailoğlu, 2020).

Özellikle 2020 senesinden bu yana tüm dünyada etkileri fazlası ile hissedilen COVID-19 salgını sebebiyle pek çok sektörde olduğu gibi sağlik sektörü de çok köklü değişiklikler geçirdi. Dijital tarafta sağlık sektörü aslında çok geniş bir yelpazede ele alınabilir. Sağlık kuruluşları tarafı yani hastaneler, klinikler başlı başına bir sektör iken özellikle kişilerin evde kalmaları sebebiyle hareketsiz kalmaları ve beslenmeleri konusunda da bir takım sağlık hizmetlerini mobil cihazları yardımıyla almaya başlaması da bu kapsamda ele alınabilir. Özellikle formda kalmak, beslenme tüyoları almak gibi sebeplerle günümüzde on binlerce sağlık aplikasyonu geliştirilmiş durumda. Örneğin Statista tarafından 2015'in ilk çeyreğinden 2020 son çeyreğine kadar Google Play Store'da bulunan mobil sağlık aplikasyon sayısındaki değişim kayda değerdir, çünkü ortalama her yıl 50bin aplikasyonun pazarda yerini aldığı görülmektedir.

Sağlık işletmeleri tarafında hastanelerin dijitalleşme süreci de son senelerde oldukça kayda değer gelişmeler göstermektedir. Türkiye açısından ele alındığında devlet hastaneleri genel manada devlette meydana gelen dijitalleşme hizmetleri ile sürecin içine dahil olurken özel hastaneler ve klinikler aynı süreç içerisinde özellikle sağlıkla ilgili yapılan işlem kayıtları tarafında yer alırken ayrıca kendi dijitalleşme faaliyetlerini de sürdürmektedirler. Ülkemizde 2010 itibari ile tüm hastanelerin ortak bir ağa bağlanması Hastane Bilgi Yönetimi Sistemi (HBYS) ile başlamıştır. Belirtilen sistem hastanelerde yapılan işlemleri bilgisayar üzerinde gerçekleştiren yazılım grubu olarak tarif edilmektedir (Dijital Hastane, 2015). Aslında devam eden süreçte online randevu alınmasından, kişilerin kendilerine yapılan tahlilleri, gerçekleştirilen işlemleri, teşhisleri görebilmeleri gibi pek çok alanda dijitalleşme yaşandı. Bu genel işlemler de bilgi toplumu uygulamaları çerçevesinde Elektronik Sağlık Kaydı (ESK) tutulması bağlamında değerlendirilebilecek online sağlık işlemleri olarak ele alınabilir.

Hastanelerin dijitalleşme sürecinde genel manada bilgi ve iletişim teknolojilerinin (BIT/ICT) hem hastalar hem de çalışanlar için kullanılmaktadır. Bu şekilde hizmet veren hastaneler ise dijital hastane olarak kabul edilmektedir. Türkiye' de sağlık hizmeti sunan kuruluşlar sağlıkta dönüşüm projesi ile birlikte dijitalleşme sürecine girmişlerdir (Peker, Giersbergen ve Biçersoy, 2018). Ancak şunu belirtmekte fayda vardır: bu sürecin meydana getirdiği değişikliklerin hem sağlık profesyonelleri hem de vatandaşlar tarafından tam anlamı ile benimsenerek sürdürülebilir hale gelmesi için sürecin tüm bileşenlerinin tam olarak anlaşılması aynı zamanda sürecin şeffaf bir şekilde bu hizmetler faydalananlar lehine yanlış bilgilendirme ve hile yapılmadan devam etmesi önemlidir. 
Bu çalışmada da sağlık hizmetleri dijitalleşme kapsamında ele alınmadan önce pazarlama ve pazarlamanın dijitalleşmedeki öneminden bahsedilmiş, ayrıca hile kavramı, hile ve dolandırıcılığın sağlık hizmetlerinde yol açtığı olumsuz durumlar hem geleneksel sağlık hizmetlerinde hem de dijital kanallarda açıklanmıştır.

\section{2- Pazarlama ve Pazarlamada Hile}

Pazarlama çok uzun zamandan beri hayatımızda var olan, özünde işletmenin tüketiciler için bir değer oluşturmasına dayanan ve işletmenin tüm süreçlerini ilgilendiren ve onlar üzerinde etkisi olan geniş bir kavramdır. Pazarlama anlayışının temelinde tüm işletme süreçlerinin müşteri gibi düşünüp, işbirliği gerçekleştirmeleri ve bu doğrulta müşteri ihtiyaç ve beklentilerini tatmin etme amacı bulunur. Dolayısıyla sorumlu pazarlamacılar müşterilerin isteklerini keşfederek onlar için bir değer yaratıp bunun karşılığında da kendileri için değer elde edecekleri ürün ya da hizmetler sunarlar. Tanımsal olarak incelendiğinde pazarlama kavramı Amerikan Pazarlama Derneği'nin (AMA) tanımına göre "Tüketiciler, müşteriler, ortaklar ve toplumun tümü için değer yaratan teklifleri oluşturan, iletişimi yapan, dağıtan ve değişimini gerçekleştiren faaliyetler, kurumlar ve süreçlerdir". Aslında bu tanımdan da yola çıkıldığında yine değer kavramı ön plana çıkarken pazarlamanın çok genel manada tanımlandığında sadece işletmenin müşterileri değil tüm paydaşlar için bir değer yaratmayı hedeflediği, dolayısıyla bu durumun da işletme içerisinde gerçekleşen tüm süreçlerin evrelerinde pazarlamanın yer aldığının bir kanıtı niteliğindedir. Yani ürün ya da hizmetin henüz düşünce aşamasındayken başlayan pazarlama satış gerçekleştikten sonra da devam eden bir döngü halinde sürer.

Pazarlamada belirtilen tüm bu sürecin gerçekleşmesi için pazarlamanın temel başlangıç noktasının insanlarla arasında güven inşa etme üzerine kurulu olmasının önemi çok büyüktür. Dolayısıyla belirtmekte fayda vardır ki pazarlamanın amacı asla tüketiciyi aldatmak değil, aslında onlarla arasında güven inşa etmektir. Ancak, bazı işletmelerde pazarlama faaliyetlerinde tüketici çıkarlarından ziyade işletme çıkarları ön plana çıkmakta ve şüpheli bazı pazarlama uygulamaları gerçekleşebilmektedir. Oysa günümüzde çok önemli bir hale gelen sürdürülebilirlik, pazarlamada da oldukça geniş yer bulmaktadır. Dolayısıyla, pazarlama faaliyetinde bulunan kişi ve kurumların da verdikleri hizmetleri sürdürülebilirlik kapsamında ele alarak sunmaları çok önemlidir (Kotler ve Armstrong, 2017).

Maalesef günümüzde tüketici çıkarlarını olumsuz etkileyen aldatıcı uygulamalar kapsamında konuşulabilecek, pazarlama etiği içerisinde yer bulan ve "pazarlama hileleri" olarak tabir edilen yabancı literatürde de "marketing fraud" olarak geçen kavramla bazı alanlarda karşılaşılma sıklığı artmaya başladı. Hile ya da dolandırıcılık zarar verme niyetiyle bir başkasının kasıtlı olarak aldatılması olarak tanımlanmaktadır. Verilen zararın fiziksel hasar olması gerekmez, hatta bu zarar genellikle finansal olmaktadır (Legal Information Institute, 2020).

Hile kavramı genel manada insanların aldatılması olarak açıklansa da literatürde hile kavramının ait tanımlamalara bakmakta fayda görülmektedir. Bunlar;

- Bir başkasını kendi lehine hareket etmeye ikna etmek için gerçeğin bilerek yanlış beyan edilmesi veya maddi bir gerçeğin gizlenmesidir

- Haksız veya yasa dışı bir avantaj elde etmek için birini kasıtlı olarak aldatma suçudur (Rahman ve Duri, 2020).

- Bir kişinin yanlış olduğunu bildiği veya doğru olduğuna inanmadığı ve aldatmanın kendisine yetkisiz bir fayda sağlayabileceğini bilerek yaptığı kasıtlı aldatma veya yanlış beyandır (Thornton vd., 2013).

Hile kavramı bazen hata kavramı ile karıştırılabilmektedir. Dolayısıyla bu iki kavramı ayırt edebilmek için hile kavramının kendine özgü bazı nitelikleri bulunmaktadır. Bunlar arasında 
karşı tarafı aldatma amacıyla gerçekleştirilmesi, gizli yapılması, sonucunda karşı tarafın ya da işletmenin zarar görmesi, hileyi yapan kişinin kendisine çıkar sağlamayı amaçlaması ve kasıtlı, bilinçli olarak geçekleştirilmesi sayılmaktadır (Akçay ve Uysal, 2019).

Pazarlamada hile kavramı incelendiğinde temel olarak pazarlama karması unsurları ile ele alınabilir. Bu noktada temel pazarlama karmasını oluşturan ürün, fiyat, dağıtım ve tutundurma alanında tüketicilerin burada yapılacak hilelerle aldatılma ihtimalleri bulunabilir (https://courses.lumenlearning.com, 2016).

Ürün ya da hizmet unsuru tarafından ele alındığında ürünün ya da hizmetin tüketici beklentisine uygun bir şekilde tasarlanmış olması, üretilmesi önem kazanırken aynı zamanda da tüketicilerin ürünün bazı tavsiye edilmeyen kullanımları hakkında uyarılıp uyarılmadığı gibi konular öne çıkmaktadır. Aynı şekilde ürünün paketlenmesi da burada yer alacak unsurlardandır, paket içeriği, ürün boyutu hakkında tüketicilere hile yapılmaması, aldatılmaması önemli bir konudur.

Fiyatlandırma tarafında ise uygulamada pek çok farklı uygulama ile karşılaşmak mümkün. Maalesef bugün pek çoğumuz indirim dönemlerinde ürünün fiyat etiketinde üzeri çizili fiyatın aslında onun normal fiyatının çok üzerinde olduğunu ve indirimli fiyatının da olması gereken fiyat olduğundan haberdarız. Bunu yapmayan gayet dürüst işletmelerin de olacağı aşikâr, ancak aldatıcı uygulamalar o kadar yaygınlaşmış olması sebebiyle dürüst davrananların da var olabileceğini maalesef düşünemiyoruz. Dolayısıyla fiyat unsuru ele alındığında fiyatın müşteriye adil bir şekilde sunuluyor olması, üründen tahsil edilen fiyatın ilan edilen fiyatla aynı olması gibi durumlar öne çıkmaktadır.

Tutundurmada ise tüketiciye yönelik olarak tanıtımda kullanılan ifadelerdeki iddiaların doğruluğu öne çıkmaktadır. Ürün ya da hizmetin özellikleri, performansı hakkında doğru bilgiler vermek gerekmektedir. Tutundurma tarafında ülkemizde bazı yaptırımlar uygulansa da diğer pazarlama karması unsurları düşünüldüğünde çok sıkı yaptırımlar olmadığı görülmektedir. Mesela sağlık alanında pazarlama faaliyetleri belirli kısıtlara tabidir ve reklam uygulamalarında özellikle yasaklar bulunmaktadır. Bu noktada Türk Tabipleri Birliği, Reklam Özdenetim Kurulu ve Rekabet Kurumu yaptırımlar uygulayabilmektedir. Bu noktada doktorlar ile sağlık kuruluşlarının yasal düzenlemeler çerçevesinde kalmak şartı ile bilgilendirme amaçlı ilan verebileceği, ancak bunların reklam özelliği taşımaması gerektiği vurgulanmaktadır (Giritlioğlu, 2017).

Pazarlama karmasında dağıtım unsuru ele alındığında ise ürün ya da hizmetin tüketiciye vaat edilen kalitede ve fiyatta ulaştırılması sorumluluğunu üstlenmesi gerekliliği vurgulanmaktadır. Dünya geneline bakıldığında Amerika Birleşik Devletleri hile ya da aldatıcı uygulamalar konusunda hem düzenlemeler hem de yaptırımlar itibari ile ileri bir seviyededir. Federal Ticaret Komisyonu (FCT) bu konuda 1983 yılından beri yapılan haksız ya da aldatıcı uygulamalar ile ilgilenmekte ve cezai yaptırımlar uygulamaktadır. Örneğin FTC, bir şirketin reklamlarında gerçeği yansıtmadığını tespit ederse, federal bölge mahkemesinde, şirketin reklam yayınlamayı durdurmasını gerektiren bir dava açarlar. Dava neticesinde çoğu zaman şirketler para cezası ödemek ve reklamlarını revize etmek zorunda kalabilir (Duggal, 2019). Pazarlamada hile/dolandırıcılık söz konusu olması için öne çıkan anahtar kelime kasıtlı aldatmadır. Bir pazarlama dolandırıcılığı davasında karar vermesi istenen bir yasal merciinin, aldatmanın kapsamını ve aldatmanın tüketici üzerindeki etkisini değerlendirebilmesi gerekir.

\section{3- Sağlık Hizmetlerinde Dijital Pazarlama}

Birçok alanda geleneksel süreçlerin dijitale taşınması ile birlikte kurumların müşterilerle bağlantı noktaları da farklılaşmaya başladı. Bu noktada pazarlama faaliyetleri için faydalanılan yeni pek çok araç devreye girmiş durumda. Kurumların web siteleri, sosyal medya hesapları dijital 
kanallarda müşterileri ile en çok temas kurdukları alanlar olarak karşımıza çıkıyorlar. Bireyler artık sağlıkla ilgili bir sorun yaşadığında doğrudan hastaneye ya da bir kliniğe gitmek yerine öncesinde bir araştırma gerçekleştiriyorlar. Dolayısıyla dijitalde bireylerle temas noktalarını hem artırmaları hem de içerik açısından zenginleştirmeleri işletmeler açısından oldukça önemli. Bu noktada TÜİK'in düzenli olarak gerçekleştirdiği Hanehalkı Bilişim Teknolojileri Kullanım Araştırması Türkiye'de internet kullanan bireylerin \%65,4'ünün interneti sağlikla ilgili bilgi aramak amacıyla kullandıklarını göstermektedir (TÜİK, 2020). Dolayısıyla sağlık hizmeti veren kurumlar tüketicilerin karar verme süreçlerine destek olup kolaylaştırmak adına dijital kanallardan faydalanmalıdırlar.

Kurumların ürün ve hizmetleri hakkında bilgi verdikleri, tutundurma faaliyetlerini yürüttükleri, satış ve satış sonrası destek hizmetini gerçekleştirdikleri bu mecralar günümüzde pazarlama faaliyetlerindeki tüm süreci içerisinde barındırmaktadır. Pek çok sektörde olduğu gibi sağlık sektörü için de bu kanallar artık bir tercihten öteye geçerek zorunlu birer mecra haline gelmiş durumdalar. Sağlık kuruluşları daha önceki başlıkta bahsedildiği üzere süreçlerinde dijitalleşmeye gitmenin de ötesine geçerek pazarlama faaliyetleri için de dijital kanalları kullanmaya başlamışlardır. Pazarlama bu noktada sağlık profesyonellerinin hedef pazarları için değer yaratmalarına yardımcı olmada önemli bir rol oynamaktadır.

Bu noktada kullanıcı dostu ve mobil uyumlu bir web sitelerinin olmasının yanısıra sosyal medya hesaplarının da aktif bir şekilde kullanılıyor olması önem kazanmaktadır. Dijital pazarlama platformları arasında oldukça önemli bir yeri olan sosyal medya, müşterilerle iletişim kurmak için önemli kanallar olarak görülmelidir. Sosyal medya kanalları bireylerin sağlık sorunlarıyla ilgili güncel konulardan haberdar olmaları için kullanılan alanlardan bir tanesidir. Geleneksel pazarlama kanallarıyla karşılaştırıldığında, dijital platformlar daha ilgi çekici, daha kişiselleştirilmiş, etkileşimli ve duygusal içerik tasarlamak için daha fazla olanak sunmaktadır.

Dijital pazarlama; sosyal medya pazarlaması, mobil pazarlama, affiliate (satış ortaklığı) pazarlaması, arama motoru optimizasyonu (SEO-search engine optimization), içerik pazarlaması, arama motoru pazarlaması, online reklam, online itibar yönetimi gibi elemanları içerek şekilde geniş bir kapsamda ele alınabilir (Khatua, Das ve Dash, 2020). Elbette bunları gerçekleştirebilmek için temelde kurumun bir web sitesi, sosyal medya hesapları, bunlara ek olarak günümüzde insanların artık $\% 70$ hatta $\% 80$ gibi oranlarla arama faaliyetlerini mobil cihazları üzerinden gerçekleştirildiği de düşünülürse sağlık işletmelerinin mobil aplikasyonlarının da var olması ön koşullardandır. Sağlık sektöründe de pazarlama faaliyetlerinde bu kanallardan faydalanılmaktadır. Çünkü müşterilere dijital pazarlama faaliyetleri sonucunda temas edilecek noktalar arasında bu kanallar gelmektedirler.

\section{4- Sağlık Hizmetlerinde Hile}

Sağlık hizmeti sahtekarlığı, sağlık hizmeti sağlayıcıları, hastalar ve sağlık sistemini yasa dışı yardımlar veya ödemeler almak için kasıtlı olarak aldatan diğer kişiler tarafından gerçekleştirilebilir. Sağlık hizmetlerinde hile ve dolandırıcılık kavramı aslında tüm dünyada var olan bir problemdir. Sağlık alanındaki hileleri konu aldıkları çalışmalarda bu alanda gerçekleştirilen çalışmaları incelenerek sağlıkta yapılan hileler gruplandırmışlardır (Thornton vd., 2015; Peck ve McKenna, 2017; Akçay ve Uysal, 2019). Buna göre sağlık alanındaki hilelerden bazıları şu şekilde özetlenebilirler:

- Rüşvet şeması olarak adlandırılan sağlıkçıların komisyon alması durumları. Bu durum farklı şekillerde hayat bulabilmektedir. Doktorlar hileli bir şekilde komisyon aldıkları ilaçlar için reçete yazabilirler. Benzer şekilde eczacilar da bir reçeteyi, ilaç şirketinden komisyon alabilmek için muadil ilacı verme eğiliminde olabiliyorlar. 
- Doktorun hastalarını maddi ilişki içinde olduğu bir kliniğe, hastaneye, laboratuvara vb. sevk etmesi. Burada sevk edilen doktora bir komisyon ödenmesi durumu söz konusu ise ilk maddede bahsedilen durum kapsamında da ele alınabilmektedir.

- Tıbbi ekipman veya sağlık hizmetleri sağlayıcıları, belirli müşteri grupları için fiyatları manipüle edebilir.

- Ayrıştırma olarak isimlendirilen, normalde birlikte gruplandırılması gereken hizmetler veya sarf malzemeleri için ayrı talepler oluşturularak hile yapılabilir. Doktorların tek seferde yapabilecekleri işlemleri ayrı olarak birden fazla yapılmış gibi göstermeleri de bu kapsamda ele alınmaktadır.

- Hayali faturalandırma yoluyla sağlık hizmeti sağlayıcıları, yapmadıkları bir işlemi faturalandırabilirler, tıbbi olarak gereksiz hizmetleri yalnızca sigorta ödemeleri oluşturmak için yapmış gibi gösterebilirler ya da çift faturalandırma yoluyla yaptıkları bir işlemi birden fazla faturalandırma yoluna gidebilirler. Benzer şekilde gerçekte sigortalı tarafından kullanılmamış bir hizmeti kullanılmış gibi gösterebilirler.

- Hastayı iyileştirmek için gerçekte ihtiyaç duyulandan daha fazla sağlık hizmeti sağlanmış olabilir, böylece gereksiz bakım sağlanarak hile yapılmış olabilir.

- Hile durumu hasta tarafından da gerçekleştirilebilir. Örneğin acı çekiyormuş gibi yapmak veya bir doktora rüşvet vermek işe yaramazsa, bir kişi, istenen reçeteleri verecek başka bir doktor arayabilir. Böyle bir hasta, reçete almak için birden fazla doktoru ziyaret ederek reçeteler yazdırabilir.

- Benzer şekilde yine hasta tarafında gerçekleşebilecek hileler arasında kimlik sahtekarlığ 1 sayılabilir. Sigortasız bir kişinin hizmet almak veya belirli bir hastalığı gizlemek için sigortalı bir kişinin kimliğini kullanması durumunda gerçekleşebilir.

Sayılan bu hilelerden daha çok hileli tazminat talebi yaratmak ve gerçekte hak edilmemiş tazminat talebi alabilmek amacıyla yararlanılmaktadır. Birden fazla faturalandırılan sağlık hizmetlerinin verilen hizmetten daha pahalı bir hizmet sunulmuş gibi yansıtılmasıla sigorta kapsamında olmayan işlemler de sigorta kapsamında gösterilebilmektedir (Mengi, 2013).

Ülkemizde sağlık sektöründe hile ve dolandırıcılıkla alakalı çalışmalar gerçekleştirilmiştir, çalışmalar hem hastaneler özelinde hem de çeşitli sigorta hizmetlerini kapsayacak nitelikte oldukları görülmektedir (Mengi, 2013; Erdoğan ve Mengi, 2018; Cömert ve Kaymaz, 2019; Akçay ve Uysal, 2019).

\section{5- Dijital Sağlık Hizmetleri ve Hile}

Sağlık hizmeti sunan işletmelerin müşteriler ile dijital ortamda temas kurdukları kanallar daha önce de belirtildiği üzere web siteleri, sosyal medya hesapları, mobil aplikasyonları temelinde özetlenmektedir. Bu kanallar üzerinden de bireylere ulaşmak için çeşitli dijital pazarlama faaliyetleri sürdürülmektedir. Hem bu kanallarda hem de dijital pazarlama faaliyetlerinde kişilere, doğru, güvenilir bilgi verilmesi, bu kişilere gerçeğin bilerek yanlış beyan edilmemesi veya maddi bir gerçeğin gizlenmemesi gerekmektedir. Onun haricinde bu kanallar üzerinden gerçekleştirilen işlemlerde benzer şekilde hassas olunması gerekmektedir. Yani hile ya da dolandırıcılık olarak ifade edilen işlemlerden uzak durulması önem kazanmaktadır.

Bu konuda Journal of Medicine and Life'ın yönetici editörü (Purcarea, 2019) tarafından kaleme alınan makalede de günümüzde hastaların sağlık hizmetleri ve bu hizmeti sağlayanların seçimi konusunda çok fazla seçeneğe sahip olmaları sebebiyle sağlık uygulamalarının gerçekten ayırt edilmesinin tek yolunun dijital çağa uyarlanmış bir pazarlama stratejisinin yanı sıra farklılaştırılmış, akılda kalıcı ve benzersiz bir teklif sunmaları olduğunu vurgulanmaktadır. Burada da bu değer yaratacak teklifin rakiplerden farklı olması, hedef kitle için önemli olması, 
taklit edilmesinin zor olması, akılda kalıcı olması gibi bilinen unsurlarının yanısıra mutlaka doğru ve gerçek olması gerekliliğini vurgulamıştır.

Dijital kanallarla birlikte bazı avantajlar gelmiş olsa da hile ve dolandırıcılık manasında bazı dezavantajlı kısımlar da bulunmaktadır. Örneğin ruhsatsız kişilerin bakım sağlaması daha kolay hale gelmesi bu konuya verilebilecek en güzel örneklerden biridir. Sağlık alanında daha önceki başlıkta da sayılan hileler dijital kanallarda da gerçekleşebilmektedirler. Ancak, dijitale özel farklılaşan durumlar da meydana gelmektedir. Sağlık ve tıp alanında dijital kanallarda hileler arasinda:

- Sağlıkla ilgili web sitelerinde ya da sosyal medya hesaplarında, gerçekleştirilen tedavilerden memnun kalındığını ya da orada satışı gerçekleştirilen bir üründen memnun kalındığını anlatan memnun müşteri videoları yer alabilir. Bu referansların gerçek olduğunu bilmek mümkün değildir. Öyle olsalar bile, gerçek ilaçların ve uygulamaların arkasında yatan bilimsel kanitların yerini tutamazlar.

- Sağlık hizmeti veren kuruluşların web siteleri ve sosyal medya hesaplarında yer alan sağlık profesyonellerinin gerçekte, web sitesinde ya da sosyal medya hesaplarında belirtilen işlemleri aslında kuruluşta gerçekleştirmemesi ya da bu kişiler dışında bireyler tarafından belirtilen işlemlerin gerçekleştirilmesi yoluyla hastaların yanlış bilgilendirilmesi ve yanıltılması durumları gerçekleştirilebilir.

- İnanılmaz sonuçlar veren mucize ilaçlar ve diğer tıbbi tedaviler vaat eden bir reklam e-posta aracılığıyla, arama motoru reklamları ile ya da sosyal medya reklamları ile karşımıza çıkabilir. $\mathrm{Bu}$ tarz hileler, alternatif tıbbın meşru bir şekli gibi görünebilen sağlık ve tıpla ilgili ürün ve hizmetleri içerebilmektedir.

- Bir başka tıbbi hile ve dolandırıcılık türü, ilaçları ve ilaçları çok ucuza veya reçetesiz sunan sahte online eczaneleri içerir. Sipariş ettiğiniz ürünleri teslim alsanız bile, bunların gerçek olduğunun garantisi yoktur. Bazı durumlarda sağlığınıza zarar bile verebilmektedirler.

- Ayrıca online işlem yaparken, online sağlık hizmetlerinden faydalanırken kişisel ve finansal verilerinizin ele geçirilme riski her zaman vardır. $\mathrm{Bu}$, bir dolandırıcının kimliğinizi banka hesaplarınızı kontrol etmek için çalmasını veya başka bir yerde finansman sağlamak veya mal satın almak için kullanmasına sebep olabilir (Action Fraud, t.y; Healthcare Global, 2020).

Dijital kanallardan biri olan mobil kanallar dijital sağllk hizmetlerinin verilmesi için kullanılan pazarlama araçlarından bir tanesidir. Burada özellikle tele sağlık ve tele tıp uygulamaları çokça kullanılmaya başlamıştır. COVID-19 salgını ile insanlar evlerinden çok fazla çıkmazlarken tele sağlık uygulamaları, sosyal mesafeyi korurken sağlık hizmetlerine erişim sağlamanın alternatif bir yolu haline geldiler. Bu uygulamalar sayesinde sağlık profesyonelleri bilgi teknolojilerinden, video görüntülemeden ve telekomünikasyon bağlantılarından yararlanarak birçok sağlık hizmetini uzaktan sunabilir hale geldiler. Ancak, tele sağlık ve tele tıp hizmetleri de beraberinde hile ve dolandırıcılıkla alakalı konuları gündeme getirdi. Burada uluslararası düzeyde karşılaşılan sıkıntılar şu şekilde özetlenmektedir (HMS, 2020a):

- Tele sağlık dışı ziyaretlerin tele sağlık hizmetleri kapsamında faturalandırılması. Ayrıca bazı durumlarda, sağlık hizmeti sağlayıcılarının, gerçekte görülmeyen hastalar için belge olmadan tele sağlık hizmetleri vermişler gibi faturalandırma gerçekleştirmeleri. Dolayısıyla hasta bilgilerini, sunmadıkları hizmetleri faturalandırmak için kullanabilirler.

- Tele pazarlama şemalarının meydana gelmesi. Tele sağlık hizmetleri sunulan kişilere ait verilerin bu hizmeti sunanlar dışındakiler tarafından ele geçirilmesi suretiyle dolandırıcıların tele pazarlama aramaları, kısa mesajlar, sosyal medya platformları ve kapıdan ziyaretler dahil olmak üzere çeşitli şekillerde insanları onların rızası dışında hedeflemesi. 
- Geleneksel tarafta da olduğu gibi bu kanalda gereksiz veya istenmeyen ilaçlar, dayanıklı tıbbi ekipman veya için laboratuvar malzemeleri ya da hizmetlerinin -siparişi veren sağlayıcı ile hastaların arasında hiçbir etkileşim olmamasına rağmen- siparişini içerebilir.

- Doktorun bir hastayı tele tıp ya da tele sağlık uygulamaları üzerinden izleyerek sonuçları alabileceği durumlarda uygulamanın bir ilaç üreticisi tarafından desteklenip desteklenmediği özellikle o ilaç üreticisinin ilacının tavsiye edilmesi noktasında önemlidir. Bu noktada kişisel bilgiler ve verilerin üçüncü tarafla paylaşılması ihtimali ortaya çıkabilir.

ABD merkezli, sağlık sisteminin ilerlemesine yardımcı olan çok çeşitli faydalar, ödeme bütünlüğü ve nüfus sağllğı yönetimi çözümleri sağlayan köklü kurumlardan olan HMS'nin (2020b) de vurguladığı üzere tele sağlık hizmetleri hakkında veri güvenliği firması CynergisTek'in gerçekleştirdiği araştırmaya göre tüketicilerin \%70'i salgın sonrası bu hizmetleri kullanmaya devam etmeyi planladıklarını söylemektedir. Bain \& Company araştırması ise, bu hizmeti sağlayanların \%80'inden fazlasının tele sağlık kullanmaya şu anda olduğundan daha fazla bir şekilde devam edeceğini belirtmektedir. Dolayısıyla giderek kullanımı artan bu kanalda hile yapılmaması adına gerekli tedbirlerin alınması önemlidir.

ABD'de 2018 yılında milyar dolarlık tele tıp kaynaklı bir hile olayında olaya karışan bütün sanıklar sağlık hizmeti sahtekarlığı, e-posta sahtekarlığı ve eyaletler arası ticarete yanlış markalı ilaçlar sokmak için komplo kurmakla suçlanarak ceza aldılar (ABD Adalet Bakanlığı, 2018). Yine ABD'de tele tıp şemalarına dahil olan 86 kişiyi içeren bir davada sanıklar arasında, herhangi bir hasta etkileşimi olmadan veya hastalarla hiç tanışmadan ve onları görmeden sadece kısa bir telefon görüşmesi ile gereksiz dayanıklı tıbbi ekipman, genetik ve diğer teşhis testleri ve ağrı kesici ilaçlar sipariş etmeleri için doktorlara ve hemşirelere ödeme yaptığı iddia edilen tele tıp yöneticileri de vardı (The National Law Review, 2021). Bu tarz dijital kanallardan kaynaklı sağlık hizmetlerinde hile olayları yaşanmakta ve sonucunda dünya çapında cezalar verilebilmektedir.

\section{6- Sonuç}

Dünya genelinde pek çok sektörde olduğu gibi sağlık alanında da rekabetin günden güne artması ile hile ve dolandırıcılık kavramları gündeme gelmeye başlamıştır. Bu noktada özellikle COVID19 salgını ile birlikte çok büyük bir gelişme gösteren dijital sağlık hizmetleri ve bu hizmetlerin bireylere ulaştırılmasında kullanılan kanallar ve pazarlama stratejilerinde doğru ve dürüst davranılması kişilerin kandırılmaması konuları özellikle önem kazanmıştır. İşletmeler açısından bakıldığında hilenin belirlenerek önlem alınması oldukça zorlu bir süreci kapsamaktadır. Hatta çoğu zaman tespit edilemeyen bu hilelerin, işletmelere verdikleri zararlar da tespit edilemeyebilmektedir (Ataman ve Aydın, 2017). Dolayısıyla işletmelerde etkin bir şekilde çalışan hile denetimi mekanizmasına dijital kanallarda da ihtiyaç bulunmaktadır.

Bu noktada sağlık hizmetlerinde hile ve dolandırıcılı̆̆ın önlenmesinde teknolojinin sağladığ faydalardan da yararlanılabileceği bazı çalışmalarda da bahsedilmektedir. Hilenin saptanmasında ve önlenmesinde makine öğrenmesi algoritmaları (Zhang vd., 2020; Bhaskar vd., 2021), blok zinciri (blockchain) kullanımı (Mackey vd., 2020) gibi yeni yöntemler öneren çalışmalar bulunmaktadır. Bunlar haricinde bireylerin tanımlama süreçlerinin geliştirilmesi amacıyla parmak izi tarayıcı, göz bebeği tarayıcı veya yüz tanıma gibi biyometrik güvenlik önlemleri, özellikle faturalandırma kısmındaki hileler için yapay zekâ uygulamaları (Matthews, 2019) gibi çözümler de önerilmektedir.

$\mathrm{Bu}$ alanda gerçekleştirilen çalışmaların oldukça yeni olduğu düşünüldüğünde sağlık alanında dijital kanallarda yaşanması muhtemel hile ve dolandırıcılık kavramları daha dikkatle ele alınarak burada gerçekleşebilecek hile durumlarını önlemeye yönelik tedbirlerin sıkılaştırılması gerektiği aşikardır. 


\section{KAYNAKÇA}

ABD Adalet Bakanlığ 1 Halkla İlişkiler Ofisi (2018). Four Men and Seven Companies Indicted for Billion-Dollar Telemedicine Fraud Conspiracy, Telemedicine Company and CEO Plead Guilty in Two Fraud Schemes. https://www.justice.gov/opa/pr/four-men-and-sevencompanies-indicted-billion-dollar-telemedicine-fraud-conspiracy [Erişim tarihi: 10.05.2021]

Action Fraud, National Fraud \& Cyber Crime Reporting Center. Health Scams. https://www.actionfraud.police.uk/a-z-of-fraud/health-scams [Erişim tarihi: 10.05.2021]

Akçay, S. ve Uysal, M. (2018). Hastane İşletmelerinde İç Denetim ve Hile Denetimi İlişkisi Üzerine Bir Değerlendirme. AÇÜ Uluslararası Sosyal Bilimler Dergisi, 5 (2), 205-225.

Ataman, B. ve Aydın, R. (2017). Hile Denetimi ve Denetçilerin Hile Tespitine Yönelik Bir Araştırma. Marmara Business Review, 2 (1), 1-23.

Bhaskar, A., Pande, S., Malik, R. ve Khamparia, A. (2021). An intelligent unsupervised technique for fraud detection in health care systems. Intelligent Decision Technologies, 15 (1), 127139.

Cömert, N. ve Kaymaz, M. (2019). Araç Sigortası Hilelerinde Veri Madenciliğinin Kullanımı. Marmara Üniversitesi İktisadi ve İdari Bilimler Dergisi, 41 (2), 364-390.

Dijital Hastane, (2015, 2 Eylül). HBYS (Hastane Bilgi Yönetim Sistemi), https://dijitalhastane.saglik.gov.tr/TR,4881/hbys-hastane-bilgi-yonetim-sistemi.html [Erişim tarihi: 15.04.2021]

Duggal, R. (2019), Consumer Behavior: A Marketer's Look into the Consumer Mind, Edify Publishing, USA.

Erdoğan, B. ve Mengi, B.T. (2018). Hata ve Hilelerin Önlenmesine Yönelik Kontroller ve Sağlık Sektörü Üzerine Bir Uygulama. Giresun Üniversitesi İktisadi ve İdari Bilimler Dergisi, 4 (8), 85-106.

Giritlioğlu, H. (2017), Sağlık Alanında Reklam Yasağı ve Nedenleri - İlan ve Bilgilendirmenin Sınırı - Tabip Odalarının Görevleri, https://www.ttb.org.tr/825ygb0 [Erişim tarihi: 30.04.2021]

Healthcare Global (2020). High profile medical scams. https://healthcareglobal.com/hospitals/high-profile-medical-scams [Erişim tarihi: 10.05.2020]

HMS-Healthcare Management Systems, (2020a). 3 Fraud Schemes Emerging from the Transition to Telehealth. https://discover.hms.com/hms-blog/telehealth-fraud-schemes [Erişim tarihi: 10.05 .2021$]$

HMS-Healthcare Management Systems, (2020b). Fraud-Proof Your Telehealth Strategy for the New Healthcare Normal. https://discover.hms.com/hms-blog/fraud-proof-yourtelehealth-strategy-for-the-new-healthcare-normal [Erişim tarihi: 10.05.2021]

Khatua, A.K., Das, J.R. ve Dash, G. (2020). Digital and Social Media Marketing: Potential to Leverage Healthcare Communication. Journal of Commerce and Management, 5, Özel Sayı, 157-165. 
Kotler, P. ve Armstrong, G. (2017), Principles of Marketing, 7th European Edition, Pearson Education Ltd., USA.

Legal Information Institute (LII) (2020), Fraud, https://www.law.cornell.edu/wex/fraud [Erişim tarihi: 04.05.2021]

Lumen Learning, Suny Marketing (2016), Principles of Marketing, https://courses.lumenlearning.com/suny-marketing-spring2016/ [Erişim tarihi: 01.05.2021]

Mackey, T.K, Miyachi, K., Fung, D., Qian, S. ve Short, J. (2020). Combating Health Care Fraud and Abuse: Conceptualization and Prototyping Study of a Blockchain Antifraud Framework. Journal of Medical Internet Research, 22 (9). doi: 10.2196/18623

Matthews, K. (2019). How To Leverage Technology Against Healthcare Fraud. Health IT Outcomes. https://www.healthitoutcomes.com/doc/how-to-leverage-technologyagainst-healthcare-fraud-0001 [Erişim tarihi: 15.05.2021]

Mengi, B.T. (2013). Sağlık Hizmetlerinde Meydana Gelebilecek Hileleri Önlemeye Yönelik Bir Uygulama Olarak Biyometrik Kimlik Doğrulama Sistemlerinin Kullanımı. Muhasebe ve Finansman Dergisi, 60, 39-50.

Peck, S. ve McKenna, L. (2017). Fraud in Healthcare. HealthManagement.org The Journal, 17, 2, 124-126.

Peker, S. V, Giersbergen M. Y. V. ve Biçersoy, G. (2018). Sağlık Bilişimi ve Türkiye' de Hastanelerin Dijitalleşmesi. Sağlık Akademisi Kastamonu, 3 (3), 228-267.

Purcarea, V.L. (2019). The impact of marketing strategies in healthcare systems. Journal of Medicine and Life, 12 (2), 93-96.

Rahman, K. ve Duri, J. (2020). Overview of international fraud operations relating to corruption, U4 Helpdesk Answer, Transparency International.

Statista, (2021). 2015 ilk çeyreğinden 2020 son çeyreğine kadar Google Play'de bulunan mobil sağlı aplikasyon sayısı. https://www.statista.com/statistics/779919/health-appsavailable-google-play-worldwide/ [Erişim tarihi: 05.05.2021]

Şimşek, P. ve Karaismailoğlu, D. (2020). Sağlık Hizmetlerinde Dijital Teknolojilerin Kullanımı ve Hasta Güvenliği. 2. Uluslararası İnovatif Hemşirelik Kongresi - 1. İnovatif Hemşirelik Öğrencileri Sempozyumu.

The National Law Review (2021). 2020 Fraud and Abuse Year in Review. Cilt 11, Sayı 150. https://www.natlawreview.com/article/2020-fraud-and-abuse-year-review [Erişim tarihi: 10.05.2021]

Thornton, D., Mueller, R.M., Schoutsen, P. ve Hillegersberg, J.V. (2013). Predicting Healthcare Fraud in Medicaid: A Multidimensional Data Model and Analysis Techniques for Fraud Detection. Procedia Technology, 9, 1252 - 1264.

Thornton, D., Brinkhuis, M., Amrit, C. ve Aly, R. (2015). Categorizing and Describing the Types of Fraud in Healthcare. Procedia Computer Science, 64, 713 - 720. 
TÜİK, Hanehalkı Bilişim Teknolojileri (BT) Kullanım Araştırması, 2020, Sayı:33679, https://data.tuik.gov.tr/Bulten/Index?p=Hanehalki-Bilisim-Teknolojileri-(BT)-KullanimArastirmasi-2020-33679 [Erişim tarihi: 05.05.2021]

Zhang, C., Xiao, X. ve Wu, C. (2020). Medical Fraud and Abuse Detection System Based on Machine Learning. International Journal of Environmental Research and Public Health, 17, 7265. doi:10.3390/ijerph17197265 